\title{
Primary extrahepatic hydatid cyst of the soft tissue: a case report
}

\author{
Salman Yousuf Guraya ${ }^{1 *}$, Abdu Hassan Alzobydi ${ }^{2}$ and Shaista Salman Guraya ${ }^{3}$
}

\begin{abstract}
Introduction: Hydatid disease of the soft tissue is an exceedingly uncommon site to be affected by the tapeworm Echinococcus. The presentation is often vague and misleading. The diagnostic armamentarium has to be supplemented by a meticulously taken history and clinical examination.

Case presentation: The present case report describes a 33-year-old Saudi male with a painless swelling in the right buttock which turned out to be a primary hydatid disease of the soft tissue. The lump was successfully excised surgically and the patient had an uneventful discharge.

Conclusion: Surgical excision of the extrahepatic hydatid disease remains the mainstay of treatment; although medical treatment is available for the recurrent and disseminated disease.
\end{abstract}

Keywords: Hydatid disease, Echinococcus granulosis, Soft tissue swelling, Surgical excision

\section{Introduction}

Hydatid disease is a zoonotic infection caused by Echinococcus, a cestode of the Taeniidae family [1]. It is characterized by cystic lesions occurring in different parts of the human body. The disease is common in animalraising regions and poses a significant public health problem in many areas worldwide. The disease is the most pathogenic zoonoses in the northern hemisphere with an annual incidence of 0.03 to 1.2 per 100,000 inhabitants [2]. Dairy farming seems to be a risk factor. Sixty percent of patients are involved in vocational or parttime farming, gardening, forestry, or hunting [3].

Liver is the most common organ involved (45-75\%), followed by the lung (10-50\%) [4]. The disease usually metastasizes to spleen, retroperitoneum, brain, bone, pancreas [5], and adrenal glands [6]. The current case report demonstrates hydatid disease in the soft tissue with a successful surgical cure.

\section{Case presentation}

A 33-year-old Saudi male presented to the surgical clinic of King Khalid Hospital Najran Saudi Arabia, with a slowly growing painless lump in the right buttock for

\footnotetext{
* Correspondence: drsyg7@yahoo.com

'Department of Surgery, College of Medicine Taibah University, Almadinah Almunawwarah, Saudi Arabia

Full list of author information is available at the end of the article
}

about six months. The patient complained of fatigue and recurrent episodes of low grade fever. On examination, there was a soft and cystic, non-tender lump on the right buttock measuring about $4 \times 4 \mathrm{~cm}$ (Figure 1). The overlying skin was normal without any punctum or discharge. Except for eosinophilia in the complete blood count $(\mathrm{CBC})$, the rest of baseline blood tests and chest $\mathrm{X}$-ray were normal. The enzyme-linked immune-absorbent assay (ELISA) was positive for the Echinococcal granulosis antigens. Computed tomography (CT) scan of the concerned region showed an intact cyst with thin enhancing rim containing homogenous fluid contents (Figure 2 $\mathrm{A}$ and $\mathrm{B})$. Later on, further inquiry from the patient confirmed his direct contact with the infected sheep a few months before. Surgical exploration of the mass was undertaken under general anesthesia. After appropriate packing of the surgical field with $20 \%$ hypertonic saline solution, the lump was completely excised (Figure 3). The lump was found to be a primary muscular hydatid cyst, attached to the right gluteus medius muscle, with multiple daughter cysts (Figure 4). The histopathology report detailed a circumscribed multilocular cystic lesion with a 2-mm thick fibrous wall (Figure 5). The cyst contained clear fluid with sand-like pasty material and calcified bodies. There were multiple daughter cysts with the same histological architecture. Following the surgical procedure, albendazole $10 \mathrm{mg} / \mathrm{kg} /$ day was advised for 3 


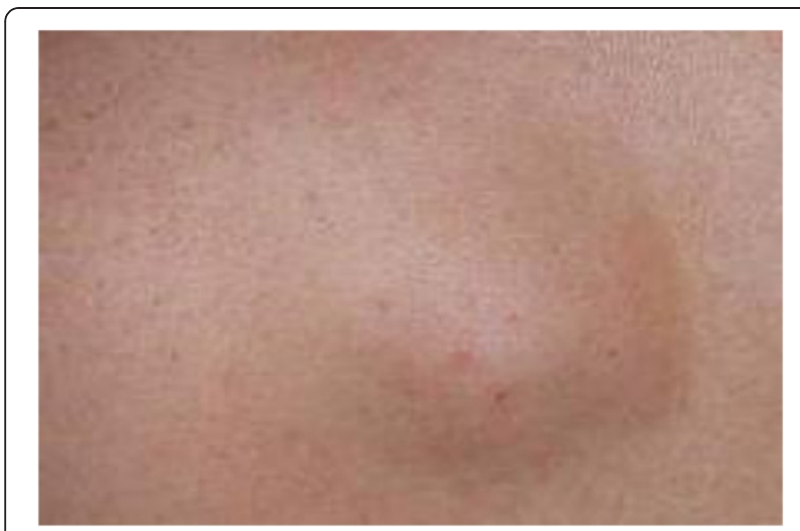

Figure 1 Preoperative view of the lump in the right buttock.

months to prevent recurrence. The patient had an uneventful recovery and was discharged home in a satisfactory condition.

\section{Discussion}

Traditionally, hydatid disease, also called hydatidosis, has two clinical categories: cystic hydatidosis caused by Echinococcus granulosus and alveolar hydatidosis caused by Echinococcus multilocularis [7]. Infection begins with the ingestion of tapeworm eggs, which in the human intestine hatch into embryos that penetrate the small bowel mucosa, enter venules and travel via portal circulation to the liver. Hydatid cysts most often develop in the liver. However when embryos pass through this first filter, the second most frequent location is the lung. Hydatid cysts can occur anywhere in the body [8].

The symptoms and clinical signs depend on the structures and organs of the body affected by the pathogens. In hepatic affection, the symptoms include cholestatic jaundice, abdominal pain, fatigue, anaphylactic reaction, and weight loss [9]. Krasnigi et al. [7] reported primary hydatid disease of the gallbladder where the patient complained of vague upper abdominal pain and dyspepsia. While coughing, chest pain, and breathlessness are

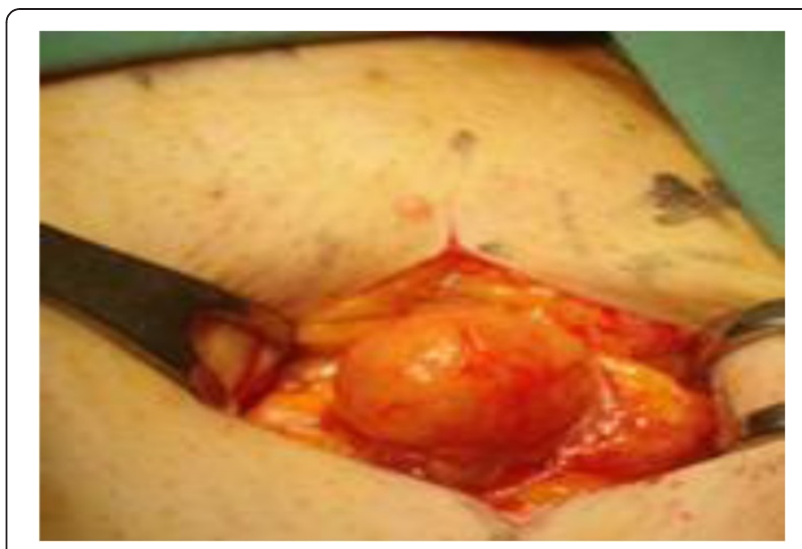

Figure 3 Per-operative view of the field showing the cystic mass being dissected.

common presenting features of the pulmonary disease, Tekinbas et al. [10] successfully treated a patient of hydatid disease presenting with massive hemoptysis. Rupture of the pulmonary cyst is reported to occur in $34 \%$ to $64 \%$ of the patients [11]. Neil et al. [2] described a case of an 80-year-old man with primary extrahepatic alveolar Echinococcosis of the lumbar spine and the psoas muscle, presenting with recurrent episodes of low grade fever and low backache. The involvement of the bone and muscle is very rarely reported in the literature. A recent study has reported a total of 22 cases with soft tissue hydatid disease; all patients were from endemic areas and most from rural regions (90\%) [12]. Most frequent locations were thigh (27\%) and gluteal region (9\%). Mean size was $2.5 \mathrm{~cm}$. Main symptom (70\%) was painless, slow growing mass with normal overlying skin. Similarly, the present case report highlights a primary hydatid disease of the muscle presenting with a painless lump.

History of animal contact (especially dogs) and living in a sheep-raising or cattle-raising rural area is generally present. A plain radiograph of the of the region may
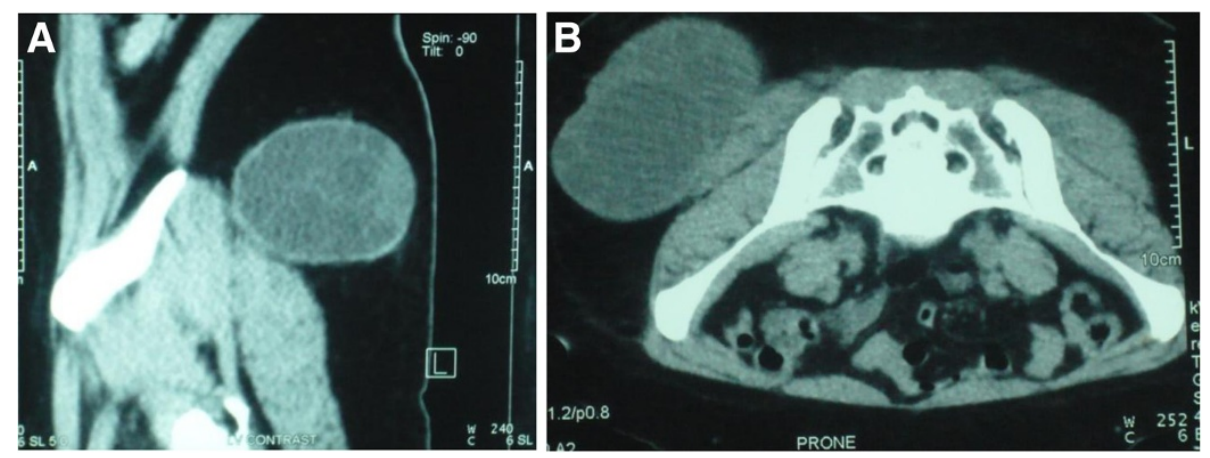

Figure 2 ( $\mathrm{A}$ and $\mathrm{B}$ ) Computed tomography; Parasagittal and axial view of the pelvis showing a cystic mass involving the right gluteus medius measuring $5 \times 6 \mathrm{~cm}$ with multiple daughter cysts inside the parent lesion. 

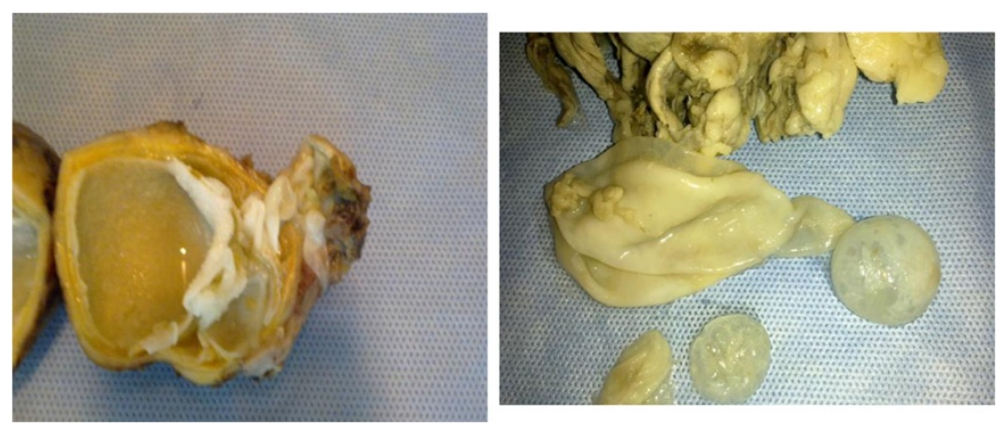

Figure 4 Cut section of the main hydatid cyst with daughter cysts.

show an unruptured cyst appearing as a spherical, wellcircumscribed, homogenous opacity, particularly pronounced if calcified. Blood eosinophilia is reported to occur in $20 \%$ to $34 \%$ of patients [13]. It is a nonspecific sign because it may be seen in numerous other pathologies. A higher rate of eosinophilia was found in patients with ruptured cysts [14]. The serological tests including Casoni intradermal skin test, Weinberg complement fixation (CF) test, indirect hemagglutination (IHA) test, ELISA, and western blot (WB) are the frequently used laboratory tests for diagnosis of hydatid disease, with the reported sensitivity of $96.7 \%, 87.1 \%$, and $100 \%$, for $\mathrm{IHA}$, ELISA, and WB, respectively [15]. Patients with a liver cyst are reported to have a higher rate of serologic test sensitivity than those having extrahepatic disease [16]. The serological tests are complementary to clinical and radiologic findings and can also be used in the follow-up of patients after surgical resection [17].

Ultrasonography (US) and CT have been reported to be the main diagnostic tools, with $85 \%$ and $100 \%$ sensitivity, respectively [18]. Although US is a reliable method for detecting echinococcal cysts, CT scans can define unique characteristics of hydatid cysts while also revealing additional small unsuspected lesions. If the cyst is intact, a CT scan with contrast enhancement may demonstrate a thin enhancing rim, calcifications, and

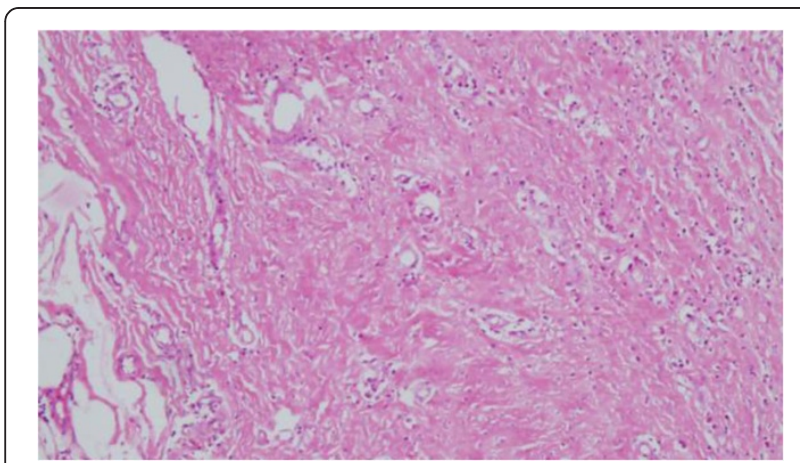

Figure 5 Histological view (hematoxylin and eosin stain X200) of the cyst showing thick fibrous wall and necrotic material. daughter cysts. All these features were clearly demonstrated in the current case. In addition, an increase in the CT density of the affected organ and/or a thick wall should not negate a diagnosis of hydatid disease. On magnetic resonance imaging (MRI), cysts show lowsignal intensity on $\mathrm{T} 1$ - weighted images and high-signal intensity on T2- weighted images [19]. In general, MRI is not used in defining a lung hydatid cyst. However, fistulization of a hydatid cyst located on the liver dome through the transdiaphragmatic way to the pleural cavity can be visualized perfectly by MRI view.

Medical treatment with an antihelmenthic agent benzimidazole compound, either mebendazole or albendazole, is usually administered for the established hydatid disease. Albendazole is known to be more effective than mebendazole [20,21]. A standard dose of albendazole is 10 to $15 \mathrm{mg} / \mathrm{kg} / \mathrm{d}$ (taken twice daily). Owing to its hepatotoxicity, a 1-week to 2-week interval should be given between 3-week and 4-week cycles and treatment may last for 3 to 6 months. In some cases, praziquantel can be added to albendazole. There are reports that antihelmintic agents can reduce the size of cysts in some cases, however the results are not satisfactory and this treatment should be limited for disseminated and recurrent cysts or in cases where surgery is contraindicated [22]. Surgical excision of the cysts is the recommended treatment [23]. Per operatively, various scolicidal agents have been used including $0.04 \%$ chlorhexidine gluconate, $20 \%$ hyperomic saline, $0.5 \%$ silver nitrate, $10 \%$ povidone-iodine, and $2 \%$ formalin. The scolicidal activity of povidoneiodine was found to be better than that of hypertonic saline in experimental studies, but iodine has toxic effects on peritoneal mesothelial cells [24]. An aspiration technique has been proposed that employs an aspiration apparatus that can contain and remove the cyst fluid by suction, thereby minimizing the risk of peritoneal contamination [25]. The surgical excision of the soft tissue affection is markedly easy and straightforward than the visceral and deeply seated cysts, especially if perforated. Overall, the reported recurrence rates of hydatid cyst in the literature vary from $6.6 \%$ to $22 \%$ [26]. 


\section{Conclusion}

To conclude, hydatid disease affects a wide range of organs and structures of the body including the soft tissue and muscle. The presentation is vague and misleading. A combination of carefully taken history, serological tests, and radiological imaging can clinch the diagnosis. The surgical therapy offers complete cure.

\section{Consent}

Written informed consent was obtained from the patient for publication of this case report and accompanying images. A copy of the written consent is available for review by the Editor-in-Chief of this journal.

\section{Competing interests}

The authors declare that they have no competing interests.

\section{Authors' contributions}

SYG conceived the idea, collected the data, and had a major contribution in writing the manuscript. SSG reported the images and improved the final layout. AHZ provided, analyzed and interpreted the patient data and helped in improving the final draft. All authors read and approved the final manuscript.

\section{Author details}

${ }^{1}$ Department of Surgery, College of Medicine Taibah University, Almadinah Almunawwarah, Saudi Arabia. ${ }^{2}$ Department of Surgery, King Khalid Hospital, Najran, Saudi Arabia. ${ }^{3}$ Department of Radiology College of Medicine, Taibah University, Almadinah Almunawwarah, Kingdom of Saudi Arabia.

Received: 27 July 2012 Accepted: 11 October 2012

Published: 26 November 2012

\section{References}

1. Kern P, Bardonnet K, Renner E, Auer H, Pawlowski Z, Ammann RW, Vuitton DA: European echinococcosis registry: human alveolar echinococcosis, Europe, 1982-2000. Emerg Infect Dis 2003, 9(3):343-349.

2. Neil M, Burgkart RH, Guntmar G, Von Eisenhart-Rothe R: Primary extrahepatic alveolar echinococcosis of the lumbar spine and the psoas muscle. Ann Clin Microbiol Antimicrob 2011, 10:13.

3. Akcay MN, Akcay G, Balik AA, Boyuk A: Hydatid cysts of the adrenal gland: review of nine patients. World J Surg 2004, 28:97-99.

4. Kolligs FT, Gerbes AL, Durr EM, Schauer R, Kessler M, Jelinek T, Loscher T, Bilzer M: 52-year-old patient with subcutaneous space-occupying lesion in brain. Internist (Berl) 2003, 44-6:740-745.

5. Suryawanshi $P$, Khan $A Q$, Jatal S: Primary hydatid cyst of pancreas with acute pancreatitis. International Journal of Surgery Case Reports 2011, 2:122-124.

6. Dionigi G, Carrafiello G, Recaldini C, Sessa F, Boni F, Rovera F, Renzo Dionigi $R$ : Laparoscopic resection of a primary hydatid cyst of the adrenal gland: a case report. J Med Case Reports 2007, 1:61-63.

7. Krasnigi A, Limani D, Gashi-Luci2 L, Spahija3 G, Dreshaj A: Primary hydatid cyst of the gallbladder: a case report. J Med Case Reports 2010, 4:29.

8. Wani RA, Malik AA, Chowdri NA, Wani KA, Naqash SH: Primary extrahepatic abdominal hydatidosis. Int I of Surgery 2005, 3:125-127.

9. Vuitton DA, Gottstein B: Echinococcus multilocularis and its intermediate host: a model of parasite-host interplay. J Biomed Biotechnol 2010, 923:193.

10. Tekinbas C, Turedi S, Gunduz A, Erol M: Hydatid cyst disease of the lung as an unusual cause of massive hemoptysis: a case report. J Med Case Reports 2009, 3:21.

11. Vasquez JC, Montesinos E, Peralta J, et al: Need for lung resection in patients with ruptured hydatid cysts. Thorac Cardiovasc Surg 2009, 57:295-302

12. Kayaalp C, Dirican A, Aydin A: Primary subcutaneous hydatid cysts: a review of 22 cases. Int J Surg 2011, 9:117-121.
13. Eckert J, Deplazes P: Biological, epidemiological, and clinical aspects of echinococcosis, a zoonosis of increasing concern. Clin Microbiol Rev 2004, 17:107-135.

14. Burgos R, Varela A, Castedo E, et al: Pulmonary hydatidosis: surgical treatment and follow-up of 240 cases. Eur J Cardiothorac Surg 1999, 16:628-634.

15. Akisu C, Bayram Delibas S, Yuncu G, et al: Evaluation of IHA, ELISA and western blot tests in diagnosis of pulmonary cystic hidatidosis. Tuberk Toraks 2005, 53(2):156-160 [in Turkish].

16. Babba H, Messedi A, Masmoudi S: Diagnosis of human hydatidosis: comparison between imagery and six serologic techniques. AmJTrop Med Hyg 1994, 50(1):64-68.

17. Gonzalez AN, Muro A, Barrera I: Usefulness of four different echinococcus granulosus recombinant antigens for serodiagnosis of unilocular hydatid disease (UHD) and postsurgical follow-up of patients treated for UHD. Clin Vaccine Immunol 2008, 15:147-153.

18. Gunay K, Taviloglu K, Berber E: Traumatic rupture of hydatid cysts: a 12year experience from an endemic region. J Trauma 1999, 46:164-167.

19. Morar R, Feldman C: Pulmonary echinococcosis. Eur Resp J 2003, 21:1069-1077.

20. Anadol D, Ozcelik U, Kiper N, et al: Treatment of hydatid disease. Paediatr Drugs 2001, 3:123-135.

21. Saimot AG: Medical treatment of liver hydatidosis. World J Surg 2001 25:15.

22. Vuitton DA: The WHO Informal Working Group on Echinococcosis. Coordinating Board of the WHO-IWGE. Parassitologia 1997, 39:349-353.

23. Defechereux T, Sauvant J, Gramatica L, Puccini M, De Micco C, Henry JF: Laparoscopic resection of an adrenal hydatid cyst. Eur J Surg 2000 166:900-902.

24. Solomkin JS, Wittman DW, West MA, et al: Intraabdominal infections. In Principles of Surgery. 7th edition. Edited by Schwartz SI. New York: McGrawHill; 1999:1515-1550.

25. Chiotis A, Tsaroucha AK, loannidis A, et al: Use of an aspiration apparatus in the surgical treatment of echinococcal cysts. Chirurgia 2003, 16:5-7.

26. Little JM, Hollands MJ, Ekberg H: Recurrence of hydatid disease. World J Surg 1988, 12:700-704

doi:10.1186/1752-1947-6-404

Cite this article as: Guraya et al:: Primary extrahepatic hydatid cyst of the soft tissue: a case report. Journal of Medical Case Reports 2012 :.

\section{Submit your next manuscript to BioMed Central and take full advantage of:}

- Convenient online submission

- Thorough peer review

- No space constraints or color figure charges

- Immediate publication on acceptance

- Inclusion in PubMed, CAS, Scopus and Google Scholar

- Research which is freely available for redistribution 